\title{
Understanding Risk and Uncertainty Management Practice in Complex Projects
}

\author{
Mundhir AL Hasani, PhD Candidate \\ Prof. Michael Regan
}

Bond University, Faculty of Society \& Design, Queensland, Australia

Doi: 10.19044/elp.v4no4a3 URL:http://dx.doi.org/10.19044/elp.v4no4a3

\begin{abstract}
The project management literature extensively documents project failures and observes that increases in project complexity have played a role in such failures. Additionally, the literature expresses concern that prescribed industry risk management standards are not sufficiently robust to assist in the management of risk and uncertainty, especially in complex projects. Yet, the management of risk and uncertainty is the cornerstone of the project manager's role. There is limited evidence in the literature of empirical research focused primarily on the management of risk and uncertainty with complex projects. This paper aims to investigate the practices used by project managers to address risk and uncertainty and to critically analyse the success of these methods in complex projects. The findings of this paper is contribute to addressing practical challenges, issues and concerns facing project managers in relation to the management of risk and uncertainty in complex project environments. Risk and uncertainty are vital elements of projects and this paper will act as a guide for the improvement of risk management and uncertainty practices and further contribute to the collection of empirical research relating to this topic.
\end{abstract}

Keywords: Risk, risk management, uncertainty, complex projects, project complexity.

\section{Introduction}

In terms of cost overrun and time delays, project failure is a common outcome and has been the subject of extensive empirical research in project procurement (Bosch-Rekveldt, 2011; Flyvbjerg et al., 2003; Morris \& Hough, 1987). The increasing complexity of modern projects necessitates a focus for a better understanding of increasing risk and uncertainty. The complexity in projects is increasing at the project level (Baccarini, 1996; Marle \& Vidal, 2016; Nguyen et al., 2015; Williams, 1999; Zhang, 2011) and many recent 
project failures can be attributed to underestimating project complexity and the mismanagement of risk and uncertainty (Bosch-Rekveldt et al., 2011). The rate at which projects are likely to fail is proportionate to the rate of increasing complexity, combined with the unsuccessful application of the generally prescribed industry risk standards (Flyvbjerg et al., 2003; Kutsch et al., 2011; Harvett, 2013; Qureshi \& Kang, 2015). This raises the question of whether the industry risk management techniques currently in use are capable of successfully handling the complexity, the operating environments and the externalities of modern projects (Bloom, 2014; Smith \& Irwin, 2006) and whether they can successfully manage risk and uncertainty in a complex operating environment (Ward \& Chapman, 2002, 2003). The correct management of these elements is a fundamental requirement for project success (Davis, 2017).

The primary focus of this paper is an understanding of project failure experienced by project managers in relation to the suboptimal application of generally prescribed risk and uncertainty management practices with projects that are highly complex in nature.

\section{Elements of Project Complexity from Literature}

The literature review points to common factors among projects to recognise project or programme complexity, such as complex characteristics, technical compliance, cost over-run, schedule conflicts and political issues (Bosch-Rekveldt et al., 2011; Obicci, 2017; Ramlee et al., 2016). There are several reasons why technical program content may become complex, such as technological and new software development, interfacing with multiple complementary projects and programs, significant systems engineering, and multiple integrated interfaces and users. This item also refers to technologies that are not fully developed and which require more iteration and development once design is completed and construction is underway (Bosch-Rekveldt et al., 2011; Safa et al., 2017). Finance is also often a complexity. This varies from project funding that is inadequate for achieving the desired requirements and how the injected money is actually scheduled for use in the project. Often this is influenced by politicians who, for a variety of reasons, have differing views of projects and their rankings. Negotiation processes within development projects that are complex can mitigate contingencies for financial loss in the testing and development stages (Obicci, 2017).

The third source of complexity is time. Time is a finite resource in all projects and plays a critical part in successful delivery of complex projects (PMI, 2017). For example, complicated or difficult processes in engineering projects can further complicate planned schedules due to unforeseen risks and impacts that are associated with them. Complex projects require the successful completion of critical tasks for the progression of project phases; many 
negative impacts can be experienced if there are interruptions in the completion of critical path tasks. To avoid these issues, complex master program plans, detailed schedules and work breakdown structures that connect all the required interfaces need to be developed (Vidal \& Marle, 2008). The influence of politics on complexity is layered, as organisations generally deal with federal, state and local governments. Projects are delivered in different policy environments, operational in many different financing arrangements, and have a range of stakeholders, parties, priorities and publics whose needs are varied. Therefore, the requirement of an extensive and detailed political strategy must be designed by the project manager to communicate efficiently with politicians and maintain a positive public image emphasising the importance of the project (Harvett, 2013; De Oliveira et al., 2017).

Each of these elements is the source of limitless variables and the variability of these is generally regarded to the cause of many project problems. Project plans should be designed to be detailed and inclusive, using the optimal mix of skills. Designing these plans to properly reduce risks is essential to maximise the benefit of opportunities without compromising the safety of the project. Project management agility is described as the ability for project managers to react quickly to the emergence of a threat or opportunity and is promoted by project performance evaluation, especially in the context of risk, uncertainty and decision-making.

This literature review examines efficient solutions to improve complex project failure. The results are mixed because not all complex projects fail. An example of this is the successful completion of the Heathrow Airport Terminal 5.

\section{Complex Systems and Project Complexity}

There is ongoing debate on the definition of complexity with projects. This is because project complexity is not easy to define and relies upon the unique circumstances of the scenario to warrant its characterisation (Johnson, 2006). The Oxford Dictionary defines the word complex as "consisting of parts" and is "intricate, exhibiting a difficulty to be analysed or disentangled." This is what is meant when complex adaptive systems are pragmatically described to be composed of a large number of components interacting with one another in a complicated fashion, where its size is larger than the total culmination of the smaller components (Ameen \& Jacob, 2009; Simon, 1969).

A system of complexity known to contain uncertainty is largely considered to have a structure, with some exceptions. A complex world is highly structured; however, is very difficult to accurately forecast certain events within an unordered world, let alone the location and time of the execution of these events (Goldenfield \& Kadanoff, 1999; Nguyen et al., 2015). There is a considerable difference in the meaning behind the terms 
complicated and complex, where complicated refers to a knowable system consisting of classifiable behaviour which can be hypothetically anticipated. Systems considered to be complex, however, are described as having an inherently contingent nature of outcomes, which commonly appear as synergistic interactions between internal parts of a coherent whole and result in the nature of the whole becoming unpredictable and possibly unknowable (Bawden, 2007; Marle \& Vidal, 2016). The increasing level of complexity in modern projects is thought to be an expected foundational parameter of systems adapting to complexity. The counterintuitive order of a complex adaptive system is one of its fundamental qualities.

As the complexity of projects increases (Chang \& Christensen, 1999; Philbin, 2008), there is a recent tendency to highlight the specific limitations that threaten the successful delivery of projects (Cooke-Davies et al., 2007; Ramasesh \& Browning, 2014). According to Love et al. (2015, p. 501) "as projects become more complex the likelihood of them experiencing overruns increases." A specific example is the Advanced Research Workshop run by NATO held in Kiev on 1996, which was aimed at modelling and managing complex projects. The workshop focused on the increasing complexity of projects where conventional techniques were proving ineffective and concluded that advanced methods for assessment and management were required (Tanaka, 2014; Williams, 1999). Baccarini (1996, p. 202) defines complexity as "consisting of many varied interrelated parts and can be operationalized in terms of differentiation and interdependency." Baccarini (1996) claims there are two exclusive forms of project complexity: organisational and technological. The interdependencies and differentiation in both of these forms are managed by the principles of integration: control, communication and coordination (Baccarini, 1996).

This work was developed by Williams (1999), who cites Baccarini's work in relation to his definition of project complexity being composed of both organisational and technological complexity. Williams combines these two forms of project complexity into a singular form, structural complexity, and relates the amount of internal objects within a system to their interdependency. The magnitude of structural complexity can have many contributors, which are often the result of multi-objective requirements, tradeoffs and the conflicting interests of stakeholders (Williams, 1999; Williams et al., 2012). The number of interdependencies existing between the system's objects does not quantify to the same relevance and importance as the definitions of their unique and specific nature (Papke-Shields \& BoyerWright, 2017; Williams et al., 2012).

The literature suggests that the three main forms of structural complexity are pooled, sequential and reciprocal output (Harvett, 2013; Nguyen et al., 2015; Williams, 1999; Williams et al., 2012). Pooled 
complexity refers to the contribution of the individual elements to the project, while sequential complexity means the conservation of information from one element to another, thereby reciprocating the complexity that describes the output of one element as the input of another. The reciprocal form of structural complexity is known to increase complexity through the interdependencies of its elements. This is due to their tendency to generate dynamic feedback. This ability is a human characteristic that conflicts with the assumptions made in the application of first-generational techniques. For instance, the Programme Evaluation Review Technique (PERT) assumes a steady progress method that is conducted throughout the entirety of a project's life cycle (PLC) (Nguyen et al., 2015; Walker et al., 2017).

The structural complexity of a project is composed of another key element, which is uncertainty. Uncertainty is a major compounding factor to the complexity of projects and as a result, it is considered to be an integral component of project complexity (De Araujo et al., 2017; Salah \& Moselhi, 2016). However, uncertainty can be viewed separately from complexity as a contributing factor alongside structural complexity to form the sum of the overall difficulties facing project management and therefore represents the entire complexity of the project (Haji-Kazemi et al., 2013; Qureshi \& Kang, 2015; Williams, 1999).

According to Pitsis et al. (2014) and Turner and Cochrane (1993), projects can be classified into two primary parameters:

- The degree of accuracy with which the objectives of the project are defined; and

- The degree of accuracy to which the tasks required to complete project objectives are defined.

Due to the wide variety of project types, the implementation of management and project start-up approaches has been required to be updated to the requirements of modern and evolving projects (Harvett, 2013).

Uncertainty is fundamental to the methods of a project. The clarity that methods offer is non-comprehensive and contributes to structural complexity due to the formation of new interdependencies from the re-planning and execution of methods (Remington, Zolin \& Turner, 2009). Uncertainty also exists in the definition of project objectives. For example, the success of the project deliverable is not clearly understood in software development, even though the operational processes are well known (Pitsis et al., 2014; Turner \& Cochrane 1993).

The objectives and specification of individuals can be difficult to define as they can change over time, especially after the review of preliminary prototypes. Changes and alterations made to project goals in the light of future uncertainty result in the increase of project complexity in two primary forms (Haji-Kazemi et al., 2013; Qureshi \& Kang, 2015; Williams, 1999): 
1. The actual process of altering project dimensions increases project complexity; and

2. The complexity of the product increases, which in turn increases the complexity of the methods and therefore the entire system.

There are two primary causes that contribute to an increase of a project's overall structural complexity: the interactions concerning product complexity and the project's complexity. As the demand for updated products increases, product models in some industries completely phase out their predecessor, and each generation of the product develops an increased structural complexity (Haji-Kazemi et al., 2013; Qureshi \& Kang, 2015; Williams, 1999).

The three most valuable concepts of complexity derived from theoretical and empirical assessments of the widely accepted model of uncertainty and structural complexity are faith, fact and interaction (Geraldi \& Albrecht, 2007; Harvett, 2013). Faith incurs high uncertainty, as is often creates something new and unique, while fact refers to the interactions with a large amount of independent information. Interaction has a reciprocal relationship with faith and fact and focuses on the interfaces between these states (Geraldi \& Albrecht, 2007; Harvett, 2013). A study conducted by researchers Geraldi and Albrecht (2007) investigated project managers operating within an engineering facility and drew conclusions from the emerging patterns of complexity during the life cycle of the project. The empirical data suggests similar patterns exist in the contribution to project complexity from the interactions that occur between fact and faith.

Philbin (2008) undertook research in the United Kingdom (UK) concerning managing the increasing complexity inherent within most engineering and technologically-based projects. Philbin prescribes a tool designed to manage the complexity of projects called the Imperial Colleges system view. This framework is composed of four primary pillars: the design for an integrated system, the integration of systems, systems architecture development and system-of-systems management, in an effort to adjust to the increase in project complexity. This framework was derived to reinforce the theory level of the systems and to develop a reciprocal relationship with the enterprise, which highlights the requirement to apply the business aspects of a project to the same level of complexity as its technical aspects (Philbin, 2008).

\section{Measuring Project Complexity}

In this section, the models designed to measure the complexity of projects are detailed, particularly the "Crawford-Ishikura factor table for evaluating roles" (CIFTER) (Aitken et al., 2007; Harvett, 2013), the "Analytic Hierarchy Process" (AHP) (He et al., 2015; Vidal et al., 2011), the "Technological, Organisational and Environmental framework" (TOE) 
(Bosch-Rekveldt et al., 2011, 2015) and "Uncertainty-Complex-Pace" model (UCP) (Lester, 2017; Shenhar \& Dvir, 1996).

The UCP model was designed by Shenhar and Dvir (1996) as a tool to quantify project complexity. The researchers use three terms to characterise the complexity of project models: assembly, system and array. The assembly is a subsystem designed for the operation of a single function, while a system is a collection of subsystems performing numerous functions. Finally, the array is defined as a vastly wide interconnecting network of collection systems programmed for a similar goal (Lester, 2017; Nguyen et al., 2015).

Recent models developed to quantify project complexity include the AHP (He et al., 2015; Videl et al., 2011) and the framework for the TOE (Bosch-Rekveldt et al., 2011, 2015). The AHP is a technique established by researchers Vidal et al. (2011). Comparisons between project size, interdependencies, variety and context-interdependence result in the measurements of project complexity. A recent case study revealed the resulting index of complexity overcame the capacity for the level of complexity and as a result the technique is considered to be reliable, intuitive and user friendly. However, there were significant inconsistencies with the study, as it was conducted in a particular context and operated with low levels of experience within the organisation, which resulted in the varied quality of comparisons made (Vidal et al., 2011).

The TOE framework analyses existing literature and case studies to characterise project complexity in the engineering industry (Bosch-Rekveldt et al., 2011, 2015). The TOE is composed of three separate categories containing a total of 50 elements, which provide a complexity footprint. The overall objective for employing this framework is to accept more efficient front-end development steps for projects of particular complexity. One of the limitations of the TOE framework is that it is not well suited for projects that are highly technical in nature (Bosch-Rekveldt et al., 2011, 2015).

The CIFTER framework is an extensive approach covering both the organisational and technical aspects of project management. CIFTER also looks at the relationships between project objects in a professional atmosphere. The CIFTER technique contributes to the "Global Alliance for Project Performance Standards" (GAPPS) and is composed of seven factors. These are the responsibility for providing stability within the scope of the project; a collection of methods, techniques and practices that define the approach for the operation of the project; the environmental, legal and social impacts that are caused from the operation of project development; the overall perceived financial impacts that will affect stakeholders; the strategic benefits of the project that are available to the organisational body; continued stakeholder interaction and cohesion in respect to the project's product 
characteristics; and a series of interfaces to facilitate interactions between the internal and external elements of a project (GAPPS, 2007).

Research into a range of projects was undertaken to test CIFTER as a technique to characterise projects in relation to their complexity. By using the CIFTER model to assess and allocate project complexity, the effectiveness of the project manager's ability to handle the assessment of complexity can be promoted (Aitken et al., 2007; Harvett, 2013; Lu et al., 2015). A significant element in this concept is that the magnitude of complexity can be characterised by the perception that people have of it (Aitken et al., 2007; Lu et al., 2015).

CIFTER is considered to be an effective tool with a composite and broad focus for assessing project management complexity. It forms part of a global standard and is a consistent and valid technique for application by both independent investigators and the project management team.

\section{Uncertainty and Risk in Complex Project}

Defining uncertainty and risk in relation to their role in project management is crucial in developing a clear and effective risk management strategy (Harvett, 2013; Sanderson, 2012; Walker et al.,2017). There are two key concepts that impact the effectiveness of describing uncertainty: the volume and complexity of information and the patterns of probability and randomness (James et al., 2006; Kaplow \& Weisbach, 2011). There are three main views on the nature of complexity: the classical mindset, which focuses on project objectives and the external environment; transition, which explores the relationship between internal and external project elements; and process uncertainty, which covers the perception that decision-making is impacted majorly by internal factors (Bloom, 2014; Jauch \& Kraft, 1986).

Uncertainty consists of ambiguity and volatility as key factors (Song et al., 2017). Ambiguity can be described as the absence of transparent data about external parameters, the uncertainty of cause-effect interactions, and the uncertainty of methods or practices and their perceived impacts. Volatility is defined as the unpredictable impacts or rates at which the environment can produce or change at and is a constant source for uncertainty surrounding unknown or future events (Carson et al., 2006; Song et al., 2017; Walker et al., 2017).

Alongside ambiguity, variability is evident in uncertainty (Smithson, 2015; Ward \& Chapman, 2003), where variability refers to scenarios that produce a wide range of values for a unique quantifiable parameter. A perfect example of this is the roll of a six-sided dice, which will always produce a single unique result. This form of uncertainty is referred to as aleatoric, which is the definition of an event with variable uncertainty within a range of foreseeable outcomes, i.e between 1 and 6 . This result is known as 'the dice 
will roll and a result between one and six will occur', but there is still uncertainty due to the variable nature of the result (Hillson, 2004; Song et al., 2017). Ambiguity, on the other hand, is used to describe the unquantifiable measure of uncertainty, where uncertainty refers to an associated meaning (Bloom, 2014; Walker et al., 2017). The problem in this scenario is that it is not the probability or particular result of an event, but rather the transparency of the event itself. This type of uncertainty is often the result of poor communication and is referred to as epistemic, meaning the vague or partial knowledge about the issue being discussed. The early stages of projects are often the phases of PLC where ambiguity and variability are most easily identified (Atkinson et al., 2006; Harvett, 2013; Pushkarskaya et al., 2015).

The importance of considering human epistemological expectations in relation to cognitive decision-making and an individual's perception of the behaviour of the future is essential in the accurate assessment of risk (Liu et al., 2016; Sambasivan et al., 2017). Inconsistencies with individuals' views on the classification of risk promotes concern that significant factors surrounding project functionality could be omitted from decision-making due to an imbalance of management attention focusing on the planning, operation and control of strategic assets (Bloom, 2014; Sanderson, 2012). Table 1 below displays a collaborative categorisation of differences between uncertainty and risk, which are characterised in relation to the assumptions held by decisionmakers (project managers) on the predictability of future events (Sanderson, 2012).

Table 1: Assumptions on the views of the decision-maker in relation to the uncertain events

\begin{tabular}{ll}
$\begin{array}{l}\text { Risk/Uncertainty } \\
\text { Category }\end{array}$ & Decision-Makers' View \\
\hline $\begin{array}{l}\text { Risk Category 1: a } \\
\text { priori probability }\end{array}$ & $\begin{array}{l}\text { The decision-maker believes they are capable of calculating the mathematical probability } \\
\text { of potential events based upon the sound application of mathematical laws and } \\
\text { algorithms. For example, the probability of rolling a one on a six-sided dice is clearly one } \\
\text { in six. } \\
\text { The decision-maker believes they are capable of attaching objective probabilities to the } \\
\text { likelihood of future events based upon evidence gathered on the statistical probability of } \\
\text { similar events in the past. For example, being struck by lightning or being involved by a } \\
\text { motor collision. }\end{array}$ \\
$\begin{array}{l}\text { Risk Category } \\
\text { statistical } \\
\text { probability }\end{array}$ & $\mathbf{2 :}$ \\
\hline $\begin{array}{l}\text { Uncertainty } \\
\text { Category } \\
\text { subjective } \\
\text { probability }\end{array}$ & $\begin{array}{l}\text { The decision-maker faces a wide range of potential future events but does not possess the } \\
\text { information required to assign an objective probability to an event, therefore they assign } \\
\text { estimates on the grounds of historical industry expectations in the subjective probability } \\
\text { on the likelihood of future events. }\end{array}$ \\
\hline $\begin{array}{l}\text { Uncertainty } \\
\text { Category } \\
\text { socialised }\end{array}$ & $\begin{array}{l}\text { The decision-maker faces a wide range of scenarios where the number or nature of future } \\
\text { events is unknown. This is not due to the difficulty in understanding the specifics of the } \\
\text { data but rather lies in the volume of relevant information available to the decision-maker. } \\
\text { It should always be clear to the decision-maker that the future is by definition } \\
\text { unknowable, a conclusion supported by the nature of the futures social construction. }\end{array}$ \\
\hline
\end{tabular}

Source: Sanderson (2012) 
As previously stated, it is highly important to assess human perceptions and reactions when managing for risk and uncertainties in complex projects (Qureshi \& Kang, 2015; Zhang, 2011). Although risk is acknowledged to be a result of uncertainty, this does not mean that risk and uncertainty are theoretically synonymous, as risk is "an outcome which can be calculated through measuring probabilities" and uncertainty "concerns the unknown future" (Rutherford, 2002, p. 182). The conclusion arrived at is that there exists a continuum between these concepts which varies in magnitude proportionate to the level of knowledge and calculations (Sanderson, 2012). Risk is the product of events regarded as having known outcomes, while uncertainty exists in events with unknown probabilities and outcomes.

\section{Conclusion}

There is limited evidence in the literature of empirical research focused primarily on the management of risk and uncertainty with complex projects. Specifically, the project manager's risk and uncertainty management practices, together with the inter-relationships between risk and uncertainty management practice and measures of complex project success. The combination of continuing project failures, increasing project complexity and inadequate risk and uncertainty management processes and practices establishes of doing this paper.

This paper discussed the elements of project complexity from literature such as, complex characteristics, technical compliance, cost over-run, schedule conflicts and political issues. In addition, the paper defined complex systems and project complexity. The three most valuable concepts of complexity derived from theoretical and empirical assessments of the widely accepted model of uncertainty and structural complexity are faith, fact and interaction. Furthermore, this paper described the measurement of project complexity by using CIFTER, AHP, TOE and UCP methods. Finally, this paper dedicates itself to investigating the practices used by project managers to manage for risk and uncertainty and examines efficient solutions to improve complex project failure.

\section{References}

Aitken, A., Crawford, L., \& Lille, E. (2007). A study of project categorisation based on project management complexity. Paper presented at the IRNOP VIII Conference (8th Annual International Research Network on Organizing by Projects).

Ameen, M., \& Jacob, M. (2009). Complexity in Projects: A Study of Practitioners' Understanding of Complexity in Relation to Exiting Theoretical Models. $\quad$ Recovered from: https://www.divaportal.org/smash/get/diva2:158819/FULLTEXT01.pdf 
Atkinson, R., Crawford, L., \& Ward, S. (2006). Fundamental uncertainties in projects and the scope of project management. International Journal of Project Management, 24(8), 687-698.

Baccarini, D. (1996). The concept of project complexity-a review. International Journal of Project Management, 14(4), 201-204.

Bawden, R. (2007). Complexity: unruly and otherwise. Perspectives in biology and medicine, 50(4), 614-624.

Bloom, N. (2014). Fluctuations in uncertainty: National Bureau of Economic Research, 28(2), 153-176.

Bosch-Rekveldt, M. G. C. (2011). Managing project complexity: A study into adapting early project phases to improve project performance in large engineering projects. TU Delft, Delft University of Technology: Delft Centre for Project Management.

Bosch-Rekveldt, M., Bakker, H., Hertogh, M., \& Mooi, H. (2015). Drivers of Complexity in Engineering Projects. In C. Schwindt \& J. Zimmermann (Eds.), Handbook on Project Management and Scheduling Vol. 2 (pp. 1079-1101). Switzerland: Springer International Publishing, Cham.

Bosch-Rekveldt, M., Jongkind, Y., Mooi, H., Bakker, H., \& Verbraeck, A. (2011). Grasping project complexity in large engineering projects: The TOE (Technical, Organizational and Environmental) framework. International Journal of Project Management, 29(6), 728-739.

Carson, S. J., Madhok, A., \& Wu, T. (2006). Uncertainty, opportunism, and governance: The effects of volatility and ambiguity of formal and relational contracting. Academy of Management Journal, 49(5), 1058-1077.

Chang, C. K., \& Christensen, M. (1999). A net practice for software project management. IEEE software, (6), 80-88.

Cooke-Davies, T., Cicmil, S., Crawford, L., \& Richardson, K. (2007). Mapping the strange landscape of complexity theory, and its relationship to project management. Project Management Journal, 29(6), 52-108.

Davis, K. (2017). An empirical investigation into different stakeholder groups' perception of project success. International Journal of Project Management, 35(4), 604-617.

De Araujo, M. C. B., Alencar, L. H., \& de Miranda Mota, C. M. (2017). Project procurement management: A structured literature review. International Journal of Project Management, 35(3), 353-377.

De Oliveira, U. R., Marins, F. A. S., Rocha, H. M., \& Salomon, V. A. P. (2017). The ISO 31000 standard in supply chain risk management. Journal of Cleaner Production, 151, 616-633.

Flyvbjerg, B., Bruzelius, N., \& Rothengatter, W. (2003). Megaprojects and risk: An anatomy of ambition. Cambridge: Cambridge University Press.

GAPPS. (2007). A Framework for Performance Based Competency Standards for Global Level 1 and 2 Project Managers Sydney: Global Alliance for 
Project Performance Standards. Recovered from: https://globalpmstandards.org/wpcontent/uploads/2014/12/GAPPS_Project_Manager_v1.1150411_A4.pdf Geraldi, J. G., \& Albrecht, G. (2007). On Faith, Fact, and Interaction in Projects. Project Management Journal, 38 (1), 32-43.

Goldenfield, N., \& Kadanoff, P. (1999). Simple lessons from complexity. Science, 284, 87-89.

Haji-Kazemi, S., Andersen, B., \& Krane, H. P. (2013). Identification of Early Warning Signs in Front-End Stage of Projects, an Aid to Effective Decision Making. Procedia - Social and Behavioral Sciences, 74, 212-222.

Harvett, G. M. (2013). A study of uncertainty and risk management practice relative to perceived project complexity. $\mathrm{PhD}$ Thesis, Bond University, Gold Coast, Australia. Retrieved from: http://epublications.bond.edu.au/theses/73/ He, Q., Luo, L., Hu, Y., \& Chan, A. P. C. (2015). Measuring the complexity of mega construction projects in China-A fuzzy analytic network process analysis. International Journal of Project Management, 33(3), 549-563.

Hillson, D. (2004). When is a risk not a risk. PM Forum - Newsletter of the Project Management Institute, 11, 8. Recovered from: http://www.who.int/management/general/risk/WhenRiskNotRisk.pdf James, S. B., Chris, R.-A., Keith, R., Peter, M. A., Lopez, A., Mark, S., \& Liz, V. (2006). Management Decision-Making: Risk Reduction through Simulation. Risk Management, 8(4), 310-328.

Jauch, L. R., \& Kraft, K. L. (1986). Strategic Management of Uncertainty. The Academy of Management Review, 11(4), 777-790.

Johnson, J. (2006). Can Complexity Help Us Better Understand Risk? Risk Management: An International Journal, 8(4), 227-267.

Kaplow, L., \& Weisbach, D. (2011). Discount rates, social judgments, individuals' risk preferences, and uncertainty. Journal of Risk and uncertainty, 42(2), 125-143.

Kutsch, E., Maylor, H., Weyer, B., \& Lupson, J. (2011). Performers, trackers, lemmings and the lost: Sustained false optimism in forecasting project outcomes-Evidence from a quasi-experiment. International Journal of Project Management, 29 (8), 1070-1081.

Lester, E. I. A. (2017). Chapter 8 - Project life cycles. project management, planning and control (Seventh Edition) (pp. 41-42). Oxford, United Kingdom: Butterworth-Heinemann.

Liu, J., Zhao, X., \& Yan, P. (2016). Risk paths in international construction projects: case study from Chinese contractors. Journal of Construction Engineering and Management, 142(6).

Love, P. E. D., Smith, J., Simpson, I., Regan, M., \& Olatunji, O. (2015). Understanding the Landscape of Overruns in Transport Infrastructure Projects. Environment and Planning B: Planning and Design, 42(3), 490-509. 
Lu, Y., Luo, L., Wang, H., Le, Y., \& Shi, Q. (2015). Measurement model of project complexity for large-scale projects from task and organization perspective. International Journal of Project Management, 33(3), 610-622.

Marle, F., \& Vidal, L.-A. (2016). Limits of Traditional Project Management Approaches When Facing Complexity. Managing Complex, High Risk Projects (pp. 53-74). US: Springer.

Morris, P.W.G., Hough, G.H., 1987. The Anatomy of Major Projects: A Study of the Reality of Project Management. Chichester: John Wiley.

Nguyen, A. T., Nguyen, L. D., Le-Hoai, L., \& Dang, C. N. (2015). Quantifying the complexity of transportation projects using the fuzzy analytic hierarchy process. International Journal of Project Management, 33(6), 1364-1376.

Obicci, P. A. (2017). Risk management strategies in public-private partnerships. Uganda: IGI Global.

Oxford Dictionary. Recovered from: https://en.oxforddictionaries.com/thesaurus/complex

Papke-Shields, K. E., \& Boyer-Wright, K. M. (2017). Strategic planning characteristics applied to project management. International Journal of Project Management, 35(2), 169-179.

Philbin, S. (2008). Managing Complex Technology Projects. Research Technology Management, 51(2), 32-39.

Pitsis, T. S., Sankaran, S., Gudergan, S., \& Clegg, S. R. (2014). Governing projects under complexity: theory and practice in project management. International Journal of Project Management, 32(8), 1285-1290.

Project Management Institute (PMI). (2017). A Guide to the project management body of knowledge (PMBOK Guide) ( $6^{\text {th }}$ ed.). Newtown Square, PA: Author.

Pushkarskaya, H., Tolin, D., Ruderman, L., Kirshenbaum, A., Kelly, J. M., Pittenger, C., \& Levy, I. (2015). Decision-making under uncertainty in obsessive-compulsive disorder. Journal of Psychiatric Research, 69, 166173.

Qureshi, S. M., \& Kang, C. (2015). Analysing the organizational factors of project complexity using structural equation modelling. International Journal of Project Management, 33(1), 165-176.

Ramasesh, R. V., \& Browning, T. R. (2014). A conceptual framework for tackling knowable unknown unknowns in project management. Journal of Operations Management, 32(4), 190-204.

Ramlee, N., Tammy, N. J., Noor, R. N. H. R. M., Musir, A. A., Karim, N. A., Chan, H. B., \& Nasir, S. R. M. (2016). Critical success factors for construction project. AIP Conference Proceedings, 1774(1), 030011.

Remington, K., Zolin, R., \& Turner, R. (2009). A model of project complexity: distinguishing dimensions of complexity from severity. Paper presented at the 
Proceedings of the 9th International Research Network of Project Management Conference.

Rutherford, D. (2002). Routledge dictionary of economics ( $2^{\text {nd }}$ ed.). London: Routledge.

Safa, M., Shahi, A., Haas, C. T., \& Hipel, K. W. (2017). Construction contract management using value packaging systems. International Journal of Construction Management, 17(1), 50-64.

Salah, A., \& Moselhi, O. (2016). Risk identification and assessment for engineering procurement construction management projects using fuzzy set theory. Canadian Journal of Civil Engineering, 43(5), 429-442.

Sambasivan, M., Deepak, T., Salim, A. N., \& Ponniah, V. (2017). Analysis of delays in Tanzanian construction industry: Transaction cost economics (TCE) and structural equation modeling (SEM) approach. Engineering, Construction and Architectural Management, 24(2), 308-325.

Sanderson, J. (2012). Risk, uncertainty and governance in megaprojects: A critical discussion of alternative explanations. International Journal of Project Management, 30(4), 432-443.

Shenhar, A. J., \& Dvir, D. (1996). Toward a typological theory of project management. Research Policy, 25(4), 607-632.

Simon, H. A. (1969). The Architecture of Complexity. Proceedings of the American Philosophical Society, 106(6), 467-482. doi: 10.2307/985254

Smith, D., \& Irwin, A. (2006). Complexity, risk and emergence: Elements of a 'management' dilemma. Risk Management: An International Journal, 8(4), 221-226.

Smithson, M. (2015). Probability judgments under ambiguity and conflict. Frontiers in Psychology, 6(674). doi:10.3389/fpsyg.2015.00674

Song, Y. I., Lee, D. H., Lee, Y.-G., \& Chung, Y. C. (2007). Managing uncertainty and ambiguity in frontier R \& D projects: A Korean case study. Journal of Engineering and Technology Management, 24(3), 231-250.

Tanaka, H. (2014). Toward Project and Program Management Paradigm in the Space of Complexity: A Case Study of Mega and Complex Oil and Gas Development and Infrastructure Projects. Procedia - Social and Behavioral Sciences, 119, 65-74.

Turner, J. R., \& Cochrane, R. A. (1993). Goals-and-methods matrix: coping with projects with ill-defined goals and/or methods of achieving them. International Journal of Project Management, 11(2), 93-102.

Vidal, L. A., Marle, F. (2008). Understanding project complexity: implications on project management. Kybernetes, 37 (8), 1094-1110.

Vidal, L. A., Marle, F., \& Bocquet, J.C. (2011). Measuring project complexity using the Analytic Hierarchy Process. International Journal of Project Management, 29(6), 718-727. 
Walker, D. H. T., Davis, P. R., \& Stevenson, A. (2017). Coping with uncertainty and ambiguity through team collaboration in infrastructure projects. International Journal of Project Management, 35(2), 180-190.

Ward, C., \& Chapman, S. (2002). Managing project risk and uncertainty: A constructively simple approach to decision making. West Sussex: John Wiley and Sons Ltd.

Ward, S., \& Chapman, C. (2003). Project Risk Management-Processes, Techniques and Insights ( $2^{\text {nd }}$ ed.) West Sussex: John Wiley \& Sons.

Williams, T. M. (1999). The need for new paradigms for complex projects. International Journal of Project Management, 17(5), 269-273.

Williams, T., Jonny Klakegg, O., Walker, D. H. T., Andersen, B., \& Morten Magnussen, O. (2012). Identifying and Acting on Early Warning Signs in Complex Projects. Project Management Journal, 43(2), 37-53.

Zhang, H. (2011). Two schools of risk analysis: A review of past research on project risk. Project Management Journal, 42(4), 5-18. 